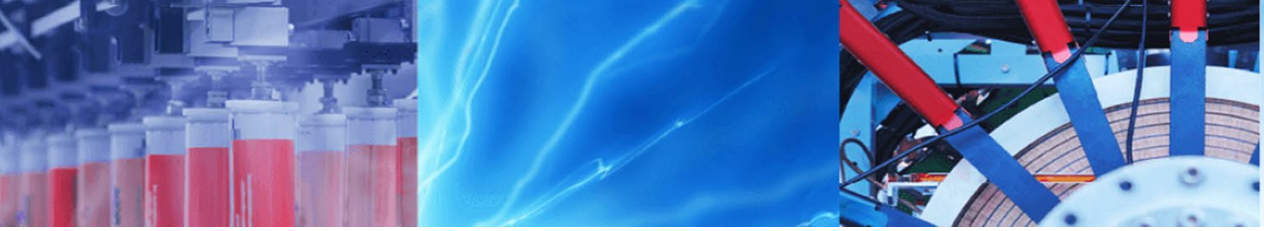

Research Article

\title{
Mechanical properties of self-compacting high-performance concrete with fly ash and silica fume
}

\author{
A. M. Falmata ${ }^{1,2} \cdot$ A. Sulaiman ${ }^{1} \cdot$ R. N. Mohamed ${ }^{1} \cdot$ A. U. Shettima ${ }^{2}$
}

Received: 26 September 2019 / Accepted: 21 November 2019 / Published online: 6 December 2019

(c) Springer Nature Switzerland AG 2019

\begin{abstract}
This paper presents the results of experimental work on the mechanical properties of self-compacting high-performance concrete (SCHPC) containing fly ash (FA) and silica fume (SF). The paper focused on the feasibility of substituting the ordinary Portland cement with waste supplementary cementing materials to decrease the abundant disposal of FA likewise improving the mechanical properties of SCHPC. Six (6) different mixes were made with $0 \%, 25 \%, 40 \%, 50 \%, 60 \%$ and $75 \%$ cement replacement by FA and SF. Test on fresh concrete such as Slump flow, L-Box, and V-funnel was conducted to assess the fresh properties of SCHPC. The mechanical properties evaluated were development of compressive strength, splitting tensile strength and static modulus of elasticity. The results of slump flow, passing ability, and viscosity indicate that it satisfied the requirement of the Specification and Guidelines for Self-Compacting Concrete. Maximum compressive strength of $79.73 \mathrm{MPa}$ was obtained by $25 \% \mathrm{PC} ; 65 \% \mathrm{FA} ; 10 \% \mathrm{SF}$ at 28 days and the cement content of this mixture is only $146.88 \mathrm{~kg} / \mathrm{m}^{3}$. The splitting tensile strength of SCHPC at the age of 28 days increases from 4.84 to $5.86 \mathrm{MPa}$, while the static modulus of elasticity values ranges between $64,685 \mathrm{MPa}$ to $86,676 \mathrm{MPa}$. The results indicated that there is a synergy between FA and SF that can provide good alternative to produce SCHPC with smaller cement content and improved mechanical properties.
\end{abstract}

Keywords Self-compacting high-performance concrete · Fly ash · Silica fume · Compressive strength · Splitting tensile strength · Static modulus of elasticity

\section{Introduction}

In recent years the utilization of industrial by-products is gaining momentum with increasing environmental awareness and its likely hazardous effects [29]. The addition of waste materials into construction product for roads, buildings and different infrastructure is amongst the commonly proposed beneficial applications. Besides decreasing the degree of waste disposed in landfills, this act reduces the utilization of naturally mined materials, thus, reducing the footprint and impact of the construction industry on the natural environment. Portland concrete (PC) is the most commonly used material for construction of built infrastructure worldwide. The production of PC consumes energy and leads to release of carbon dioxide; $P C$ is liable for approximately $5 \%$ of global carbon dioxide $\left(\mathrm{CO}_{2}\right)$ emissions, with a worldwide mean of $222 \mathrm{~kg}$ of carbon emitted per ton of PC manufactured [13, 33, 41, 45].

Self-compacting concrete (SCC) is a viscous mixture suitable for casting intricate structures and structures with congested reinforcement, with slight or without vibration, while maintaining a consistent flow free from segregation and bleeding [40,42]. Self-compacting concrete was initiated by Okomora (1986), and the model of SCC

$\square$ A.Sulaiman, arizu@utm.my; A. M. Falmata, fal_mata@yahoo.com; R. N. Mohamed, roslli@utm.my; A. U. Shettima, alishettima2@gmail.com |'School of Civil Engineering, Faculty of Engineering, Universiti Teknologi Malaysia, 81310 Johor Bahru, Johor, Malaysia. ${ }^{2}$ Department of Civil Engineering Technology, The Federal Polytechnic Damaturu, 620001 Damaturu, Yobe State, Nigeria. 
was developed in 1988 at Tokyo University. The objective was to produce a durable concrete structure by improving quality in the construction industry [32]. High-performance concrete (HPC) is a durable and abrasion-resistant concrete, which is made with low water-to-binder ratio $(\mathrm{w} / \mathrm{b})$ and cured adequately [3]. The HPC is characterized by its fluidity, high strength, and durability. Both SCC and HPC are consist of similar component which when proportioned adequately can yield a desired class of concrete [23]. Therefore, SCHPC is a new generation of concrete base on the concepts of SCC and HPC. It possessed adequate self-compact ability (i.e. filling ability, passing ability, and segregation resistance) of the SCC and the high strength and good durability of the HPC [27].

The SCHPC provided a beneficial working environment since it compacts without vibration, thus, leading to speedy construction and savings. However, due to its high cementitious content and chemical admixtures, the cost of production is high. Nevertheless, savings in labour cost and the use of mineral admixtures such as FA and SF might offset the increased cost. Moreover, the synergy of FA and SF in a ternary blend improved concrete properties and made SCHPC more economically and ecologically beneficial [39]. The application of FA in concrete has gained momentum due to its high silica content which reacts with calcium hydroxide which is produced during hydration leading to pozzolonic action. This improves the concrete strength with time. FA application in high quantities might have an effect on the early strength of concrete but it can achieve similar strength at later age. Nevertheless the incorporation of SF enhances pozzolanic activity and early strength [38].

Fly ash is derived from burning pulverized coal in an electric generating power plant. Whiles $\mathrm{SF}$ is derived from smelting process in silicon and ferrosilicon industry $[2,20$, 24]. The FA is grouped into two classes: (1) Class C; and (2) Class F. Class $\mathrm{F}$ fly ash is associated with higher pozzolanic properties with little or no cementitious properties. It is often used in the production of high-performance concrete. On the other hand, the Class C fly ash contained both cementitious and pozzolanic properties. However, the cementitious property of Class C FA is limited, unless the average particle size is equal to or less than that of cement [37]. For example, Malaysia utilizes coal-fired power plants for generating electricity. One of the four coal power plants in Malaysia known as Tanjung Bin Power Plant produces 42,000 metric tons of FA per month from burning of coal ash [1]. It is expected that the production of FA will increase as the coal-driven electricity generation is projected to increase by 2020.

Class F FA usually offer good resistance to sulphate attack and alkali-silica reaction (ASR). Most FA, tend to lower the water demand of concrete and increase its resistance to fluid flow and the ionic diffusion. The beneficial effects of FA on permeability and diffusivity become apparent with time, particularly in the case of the more slowly reacting class F FA. For instance, Thomas and Shehata [43] observed that, at early ages of 5 years, concrete containing $8 \%$ SF provides increased resistance to chlorides compared to concrete with 25\% FA due to its lower initial diffusion coefficient. Even so, at later ages variations between the chloride profiles for the two concretes become smaller because of the greater reductions in diffusivity with time for FA compared with SF. The concrete with the ternary mix has the advantage of a low diffusivity at early age and comparatibily large decay in diffusivity with time, which combine to improve the resistance to chloride penetration compared with concrete containing either FA or SF. However, drying-rewetting record of concrete before freezing and thawing has a significant effect on typical concrete, whereas silica fume concrete is comparatively unaffected. Khan and Siddique [24] in their study compared the frost resistance of Portland cement concrete to that of silica fume concrete. Results indicated that Portland cement concrete failed after 58 cycles, whereas silica fume concretes had durability factor in excess of $90 \%$ after 300 cycles. Concretes with $20 \%, 15 \%$ and $10 \%$ SF had durability factor of $92.8,93.4$, and 97.7 , respectively. This performance of SF concrete was consequent of low degree of saturation because of self-desiccation during hydration. Likewise Cwirzen and Penttala [14] observed that Surface Scaling decreased with increasing SF amount and decreasing $\mathrm{w} / \mathrm{b}$. They concluded that moderate additions of SF seemed to densify the microstructure of the interfacial transition zone. Blending of plain concrete with 10-20\% SF significantly improved the corrosion resistance. Moreover, Dotto et al. [15] also concludes that the addition of SF can be effectively used in protecting steel reinforcement against corrosion. In additition Lee et al. [28] investigates the effectiveness of SF in controlling the damage arising from sulfate attack. They observed that the incorporation of $10 \%$ SF in OPC concrete indicates no evidence of spalling and cracking up to about 1 year of exposure. Moreover, In concrete mixtures containing FA the depth of carbonation was slightly higher compared to control concrete. However the depth of carbonation was lower in concrete containg FA and SF, this is due to the fact that SF had little effect on carbonation [19].

Very few studies reported the static modulus of elasticity and splitting tensile strength of SCHPC with Class F fly ash and $10 \%$ silica fume. For instance, Safiuddin and Zain [37] investigated the individual and combine influence of SF and FA on fresh and hardened properties of high-performance concrete. Results indicated that SF improves the compressive strength, pulse velocity, dynamic modulus of elasticity. The result further 
revealed that it produced concrete with lowest levels of initial surface absorption and drying rate. While, on the contrary the properties of high-performance concrete do not improve significantly when FA alone was used, the combination of fly ash and silica fume improves the properties of high-performance concrete. Similarly, Askari et al. [5] studied mechanical properties of SCC containing FA and SF, fresh properties, compressive strength and splitting tensile strength of SCC. Results suggested that high volume FA content leads to compressive strength gain between 28 and 120 days of curing. This finding has confirmed continuity of pozzolanic activity of FA with time, however the tensile strength decreases with increase in FA. Nevertheless a 10\% SF replacement of cement improves and maintained the tensile strength of SCC containing high volume FA. Furthermore, high-volume of FA content in SCC lowers the dosage of Superplastisizer (SP) required to achieved selfcompact ability owing to the round shape of FA particles. Moreover, the unit weight of SCC mixtures decreases due to the low specific gravity of FA and SF compared to that of Portland cement.

In the same vein, Wongkeo et al. [44] explored the influence of adding 50, 60 and 70 wt\% high calcium class C fly ash and SF as replacement of Portland cement on compressive strength and chloride resistance of SCC. It was drawn that FA and SF enhance the chloride resistance of SCC at high volume replacement of Portland cement. Likewise, Yazici [47] Studied the effect of replacing cement with class C FA at replacement levels of 30 to $60 \%$ on fresh properties, compressive strength, splitting tensile strength, modulus of elasticity and durability properties of SCC, with $10 \%$ addition of silica fume and a constant $\mathrm{W} / \mathrm{b}$ ratio of 0.28 . Results indicated that the addition of SF improves the tensile strength of SCC at all FA replacement levels. Moreover, an increase in FA up to 50\% replacement level does not considerably influenced the modulus of elasticity of SCC. On the other hand, Samhitha et al. [38] developed high strength high volume FA concrete of grade M70 with the addition of $10 \%$ SF and lime, durability properties were explored. Results indicated that the water absorption and porosity of high strength high volume FA concrete reduced by $85 \%$ and $34 \%$ respectively.

The compact ability of SCHPC is influenced by the properties of the constituent materials, therefore, when a high volume of cement is replaced, the strength development of the concrete must be investigated. Hence, this study aims to examine the influence of partial replacement of Portland cement by $25 \%, 40 \%, 50 \%$, and $65 \%$ class $\mathrm{F}$ fly ash and $10 \%$ silica fume on the mechanical properties of SCHPC. It is against this background that the current study seeks to assess the mechanical properties of self-compacting high-performance concrete with FA and SF.

\section{Experimental program}

\subsection{Materials}

An ordinary Portland Cement of CEM 1 with $42.5 \mathrm{MPa}$ strength and a specific gravity of 3.15 was used to produce the SCHPC mixtures. To achieve the desired workability and consistency of SCHPC and reduce the possibility of segregation and heat of hydration, low calcium FA equivalent to ASTM C618-12a [8] Class F with a specific gravity of 2.1, obtained from a power plant at Johor Bahru was added in different percentage. Densified SF with bulk density in the range of $550-650 \mathrm{~kg} / \mathrm{m}^{3}$ and a specific gravity of 2.1-2.4 was added to compensate for the relatively low early strength of FA concrete. Ten percent (10\%) SF was added as suggested by [5]. Replacement of cement by $10 \%$ SF improveds and maintained the tensile strength of SCC containing high volume FA [5]. Sadr Momtazi et al. [36] also observes that the paste containing $10 \%$ SF had uniform microstructure and compactness in cement matrix. In addition, moderate additions of SF seemed to densify the microstructure of the interfacial transition zone. Likewise, $10 \%$ SF addition improves frost resistance of concrete with durability factor of 97.7 [24]. The incorporation of $10 \% \mathrm{SF}$ in concrete indicates no evidence of spalling and cracking up to about 1 year of exposure to sulfate attack [28]. Likewise, blending of plain concrete with $10 \%$ SF significantly improved the corrosion resistance [15].

The chemical composition of Portland cement and SCMs obtained from X-ray diffraction (XRD) analysis is presented in Table 1. According to ASTM C618-12a [8], Class F FA had a minimum composition of silicon dioxide $\left(\mathrm{SiO}_{2}\right)$, aluminium oxide $\left(\mathrm{Al}_{2} \mathrm{O}_{3}\right)$ and iron oxide $\left(\mathrm{Fe}_{2} \mathrm{O}_{3}\right)$ of $70 \%$, while the total calcium oxide $(\mathrm{CaO})$ composition is less than 7\%. This class of FA is also referred to as Low $\mathrm{CaO}$ FA [34].

Natural river sand was used for the mixtures with relative density (SSD), water absorption and fineness modulus

Table 1 Chemical composition of Portland cement and SCMs

\begin{tabular}{lccc}
\hline Component (\%) & PC & FA & SF \\
\hline $\mathrm{SiO}_{2}$ & 16.2 & 51.8 & 96 \\
$\mathrm{Al}_{2} \mathrm{O}_{3}$ & 3.52 & 26.5 & 0.1 \\
$\mathrm{Fe}_{2} \mathrm{O}_{3}$ & 2.91 & 8.5 & 0.6 \\
$\mathrm{CaO}$ & 70.9 & 4.81 & 0.1 \\
$\mathrm{MgO}$ & 0.764 & 1.1 & 0.2 \\
$\mathrm{SO}_{3}$ & 3.36 & 0.6 & 1.1 \\
$\mathrm{~K}_{2} \mathrm{O}$ & 0.572 & 3.27 & 0.4 \\
$\mathrm{Na}_{2} \mathrm{O}$ & 0.3 & 0.67 & 0.1 \\
Ignition loss & 0.7 & 1.47 & 1.7 \\
\hline
\end{tabular}


of $2.65 \mathrm{~kg} / \mathrm{m}^{3}, 1.15 \%$ and 3.17 respectively. The result of the grading of fine aggregate as determined from sieve analysis is presented in Fig. 1. The grading of the different sizes of the fine aggregate falls within the upper and lower limits specified by ASTM C33/C33M - 13 [6]. Therefore, the fine aggregate was well graded. A well-graded aggregate, usually reduces the demand for water and superplasticizer, thereby improving the packing density, flexibility, and workability of SCHPC. A well-graded $10 \mathrm{~mm}$ aggregate with relative density (SSD) and water absorption value of $2.66 \mathrm{~kg} / \mathrm{m}^{3}$ and $1.0 \%$ respectively, was used as coarse aggregate in accordance with BS 882 (1992). The third generation of polycarboxylate ether-based superplasticizer (SP) referred to as Sika Viscocrete-2044 that complies with ASTMC494 [4] was added to achieve the required consistency.

\subsection{Mix proportions and specimen preparation}

Six (6) different mixes comprising of $0 \%, 25 \%, 35 \%, 50 \%$, $60 \%$, and $75 \%$ replacement of cement by FA and SF while maintaining SF at $10 \%$ constant replacement were prepared. The water/binder $(\mathrm{w} / \mathrm{b})$ ratio was fixed at 0.31 . The third generation of polycarboxylate ether-based superplasticizer (Sika Viscocrete-2044) which complied with ASTMC494 [4] was added to increase workability of the mixture and to avoid increase of water and to achieve the required consistency. The SF exhibits the tendency to improve the pore structure of concrete and acts as a filler in enhancing the density of concrete [22]. Table 2 summarized the properties of the different mixture proportion.

The recommended dosage of superplasticizer (SP) is $1-3 \%$ by weight of cement/powder. The unit of all constituent materials were in $\mathrm{kg} / \mathrm{m}^{3}$.

Concrete was mixed using a rotary mixer of volume $0.03 \mathrm{~m}^{3}$. The mixing sequence is typical for powder type SCHPC and was based on the procedure established by Khayat et al. [25]. After mixing, slump flow, L-box, and V-Funnel tests were conducted on the fresh concrete as recommended by EFNARC [16], to explore the features of the rheological properties of SCMs. Concrete cubes of size $100 \times 100 \mathrm{~mm}$ were prepared for measuring compressive strength. The specimen was cured in water at a temperature of $(20 \pm 5){ }^{\circ} \mathrm{C}$ for 7,28 and 56 days prior to testing.
Fig. 1 Grading curve of fine aggregate in relation to ASTM C33 limits
Table 2 Mixture proportion of SCHPC

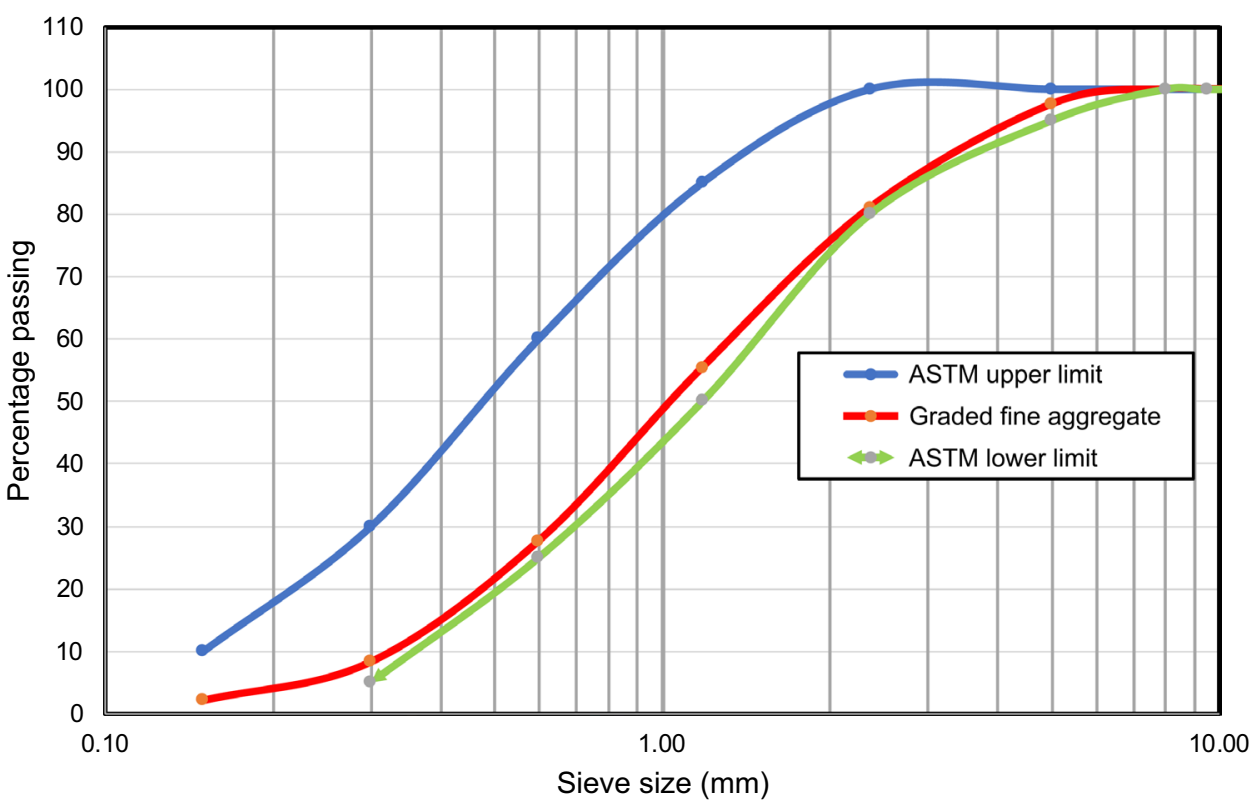

\begin{tabular}{llllllll}
\hline Concrete mix & Water & $\mathrm{kg} / \mathrm{m}^{3}$ & \multicolumn{3}{l}{ Fine agg } & Coarse agg & SP (\%) \\
\cline { 3 - 5 } W/B=0.31 & & PC & FA & SF & & \\
\hline 100\%OPC & 188 & 587.50 & 0 & 0 & 796.33 & 837.00 & $15.28(2.6 \%)$ \\
75\%PC-25\% FA & 188 & 440.62 & 146.88 & 0 & 734.50 & 837.00 & $11.75(2.0 \%)$ \\
65\%PC-25\%FA-10\%SF & 188 & 381.88 & 146.88 & 58.75 & 713.38 & 837.00 & $14.69(2.5 \%)$ \\
50\%PC-40\%FA-10\%SF & 188 & 293.75 & 235.00 & 58.75 & 675.75 & 837.00 & $15.86(2.7 \%)$ \\
40\%PC-50\%FA-10\%SF & 188 & 235.00 & 293.75 & 58.75 & 651.37 & 837.00 & $15.69(2.67 \%)$ \\
25\%PC-65\%FA-10\%SF & 188 & 146.88 & 381.88 & 58.75 & 614.27 & 837.00 & $16.16(2.75 \%)$ \\
\hline
\end{tabular}




\section{Test methods}

\subsection{Test on fresh properties}

The slump flow test was performed according to European Standard BS EN 12350-2 [11]. The workability, consistency and filling ability of SCHPC was assessed through this test. The recommended spread diameter of the fresh concrete sample ranges from 550 to $850 \mathrm{~mm}$ EFNARC [16]. The L-Box test was used to measure the passing ability of SCHPC to flow through tight openings including spaces between reinforcing bars and other obstructions without segregation or blocking [17]. The viscosity and filling ability of SCHPC was assess using a V-funnel apparatus [17].

\subsection{Compressive strength test}

A $3000 \mathrm{kN}$ capacity universal testing machine was employed to measure the compressive strength of cube specimens $100 \times 100 \mathrm{~mm}$ in accordance with BS EN 12390-3 [12]. The test was conducted at the ages of 7, 28 and 56 days. Three specimens for each batch were measured and the average value was calculated to evaluate the compressive strength, Eq. (1) is used to calculate the Compressive strength:

$f_{c}=\frac{F}{A_{c}}$

where: $f_{c}$ is the compressive strength $\left(\mathrm{N} / \mathrm{mm}^{2}\right.$ or $\left.\mathrm{MPa}\right), \mathrm{F}$ is the compressive force at failure $(\mathrm{N})$ and $\mathrm{A}_{\mathrm{c}}$ is the specimen cross-sectional area $\left(\mathrm{mm}^{2}\right)$. The operational procedure of the compressive strength test was shown in Fig. 2.

\subsection{Splitting tensile test}

The splitting tensile strength test was conducted on cylindrical specimens at the age of 28 days curing. The test was performed in accordance with the specification of ASTM C496/C496M-11 [7]. The test was conducted using the NL Compression Machine with a capacity of $3000 \mathrm{kN}$. The maximum fracture load was recorded directly from the machine. This was computed using Eq. 2:

$\mathrm{F}_{\mathrm{ct}}=\frac{2 \mathrm{~F}}{\mathrm{NLD}}$

Where $\mathrm{F}_{\mathrm{ct}}$ is the splitting tensile strength in $\mathrm{MPa}, \mathrm{F}$ is the maximum load in $\mathrm{N}, \mathrm{L}$ is the height of the specimen in $\mathrm{mm}$, and $\mathrm{D}$ is the diameter of the specimen in $\mathrm{mm}$. The operational procedure of splitting tensile strength test is shown in Fig. 3.

\subsection{Static modulus of elasticity test}

The static modulus of elasticity of the cylindrical specimens was tested at 28 days curing. An averaging axial extensometer (Epsilon 3542) was used to measure the axial displacement while the circumferential expansion was measured with a circumferential extensometer. The specimen is placed in the axial extensometer while the axial strain is measured on opposite sides of the test specimen and the output is an average of the two readings. The extensometer was linked to a chain device mounted at mid-height of the specimen around the circumferential as shown in Fig. 4b.

\section{Results and discussions}

\subsection{Fresh properties}

The slump flow of the respective SCHPC varied in the range of 550 to $650 \mathrm{~mm}$ as shown in Table 3. This range of slump flow values lies within class SF1 of EPG-SCC [17] and is an indication of good filling ability. It is consistent with most of the researches on SCHPC and is suitable for
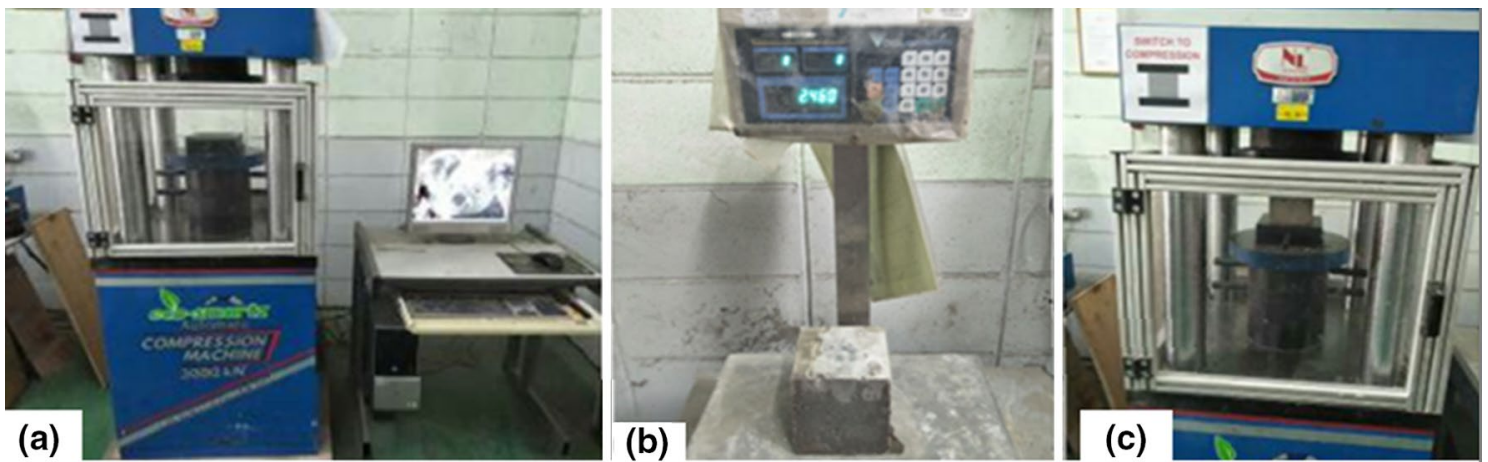

Fig. 2 a Compression test set-up, $\mathbf{b}$ weighing of the specimen prior to testing and $\mathbf{c}$ compression test on cube 

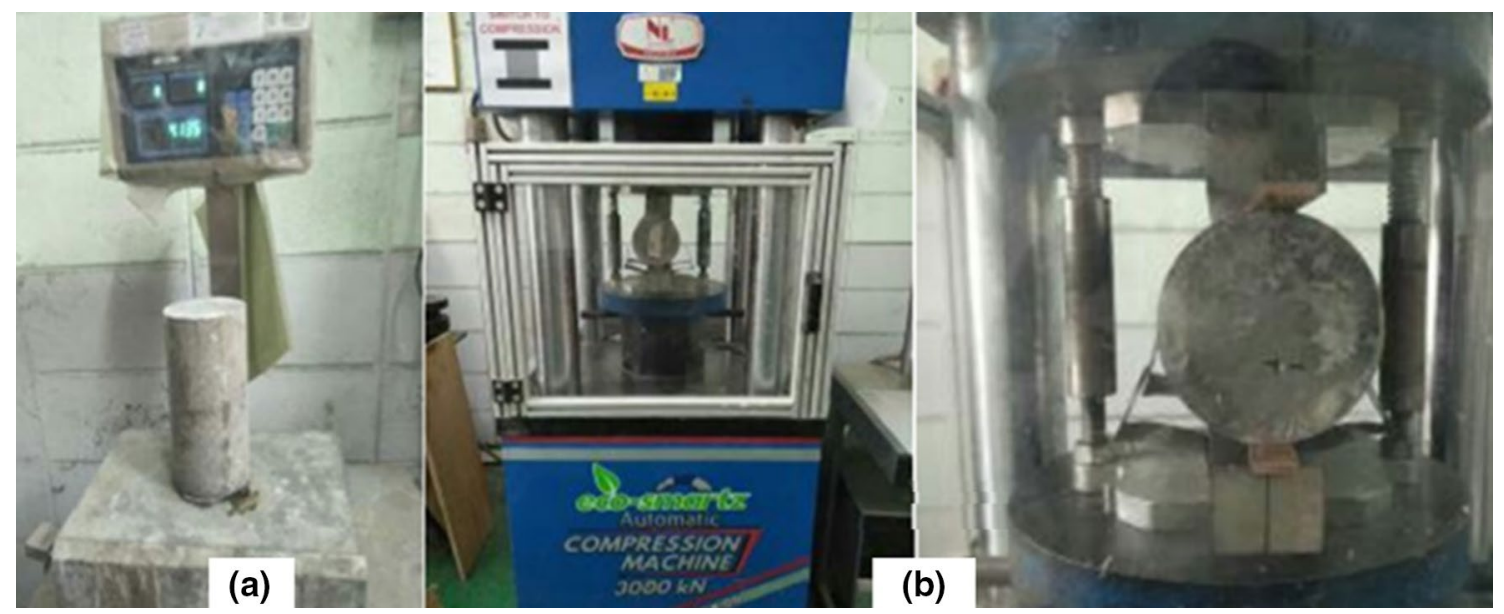

Fig. 3 a weighing of the specimen prior to testing and $\mathbf{b}$ Splitting tensile test
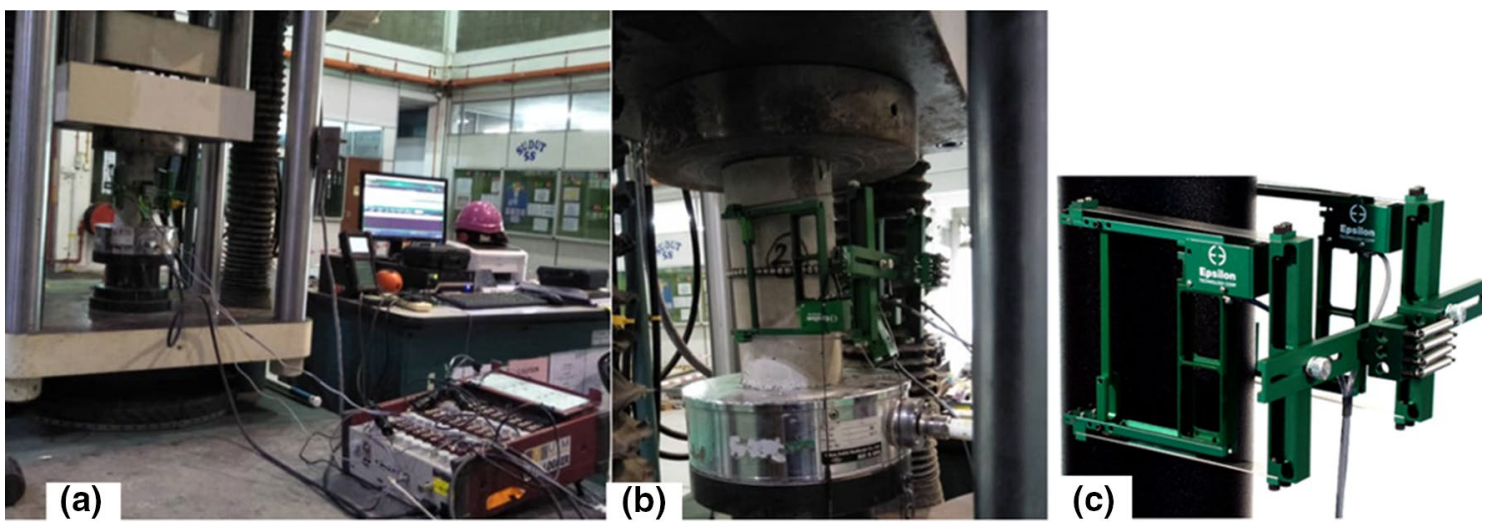

Fig. 4 a Static modulus of elasticity test setup, b Static modulus of elasticity test and c An averaging axial extensometer

Table 3 Fresh properties of concrete mixes

\begin{tabular}{|c|c|c|c|c|c|c|}
\hline \multirow[t]{3}{*}{ Concrete mixes } & \multicolumn{6}{|c|}{ Requirement limit by EFNARC [16] } \\
\hline & \multicolumn{2}{|c|}{ Slump flow (mm) } & \multicolumn{2}{|c|}{ L-box $(\mathrm{H} 2 / \mathrm{H} 1)$ ratio } & \multicolumn{2}{|c|}{ V-funnel (s) } \\
\hline & Min. & Max. & Min. & Max. & Min. & Max. \\
\hline & 550 & 850 & 0.80 & 1.0 & 60. & 12.0 \\
\hline $100 \% \mathrm{PC}$ & 550 & & 0.80 & & 12.0 & \\
\hline $75 \% \mathrm{PC}-25 \% \mathrm{FA}$ & 640 & & 0.84 & & 11.6 & \\
\hline $65 \% \mathrm{PC}-25 \% \mathrm{FA}-10 \% \mathrm{SF}$ & 600 & & 0.83 & & 11.9 & \\
\hline $50 \% \mathrm{PC}-40 \% \mathrm{FA}-10 \% \mathrm{SF}$ & 650 & & 0.87 & & 10.7 & \\
\hline $40 \%$ PC-50\%FA-10\%SF & 630 & & 0.88 & & 10.2 & \\
\hline $25 \%$ PC-65\%FA-10\%SF & 650 & & 0.88 & & 10.2 & \\
\hline
\end{tabular}

sections that are small enough to prevent long horizontal flow [10]. It was noticed that the use of class F FA in SCHPC reduces the dosage of superplasticizer needed which is followed by improved slump flow. However, a slump loss was noticed consequent of SF presence, as shown in Table 3. The concrete workability was not affected by $10 \mathrm{wt} \%$ cement replacement by SF [47].

The L-box passing ratio for the control mix is 0.76 which is approximately 0.8 . The passing ratio is between 0.84 to 0.88 for all other mixes. The range of values for

\section{SN Applied Sciences}


L-box passing ratio recommended by EPG-SCC [17] for passing ratio class PA2 is between 0.8 to 1.0. Therefore, all the SCHPC mixes satisfied the requirement for the passing ability class PA2. Moreover, the addition of FA into SCHPC improves the passing ability. This finding concurs with Nagaratnam et al. [30]. The V-funnel flow time $\left(T_{v}\right)$ of the fresh mixes varied between 10 to $12 \mathrm{~s}$. Thus, the Tv for individual SCHPC lies within the range of 9 to $15 \mathrm{~s}$ as established by EPG-SCC [17] for VF2 viscosity class. The incorporation of SF increased the viscosity of the concrete. This finding also concurs with [22]. Table 3 summarized the fresh properties of SCHPC.

\subsection{Compressive strength}

The result of the compressive strength test is illustrated in Figs. 5 and 6 . It has been noticed that the compressive strength of all SCHPC increased with increasing curing time. The compressive strength of Portland cement control is higher than the compressive strength of $75 \% \mathrm{PC}-25 \% \mathrm{FA}-$ $0 \% \mathrm{SF}$ by $35 \%$. Correspondingly, the compressive strength of $65 \% \mathrm{PC}-25 \% \mathrm{FA}-10 \% \mathrm{SF}$ is below the control specimen by $4 \%$. Conversely, the compressive strength of the control specimen is $1 \%$ higher than the compressive strength of 50\%PC-40\%FA-10\%SF and 40\%PC-50\%FA-10\%SF. However, the compressive strength of $25 \% \mathrm{PC}-65 \% \mathrm{FA}-10 \% \mathrm{SF}$ is greater than the compressive strength of Portland cement control by $2 \%$. The compressive strength of SCHPC

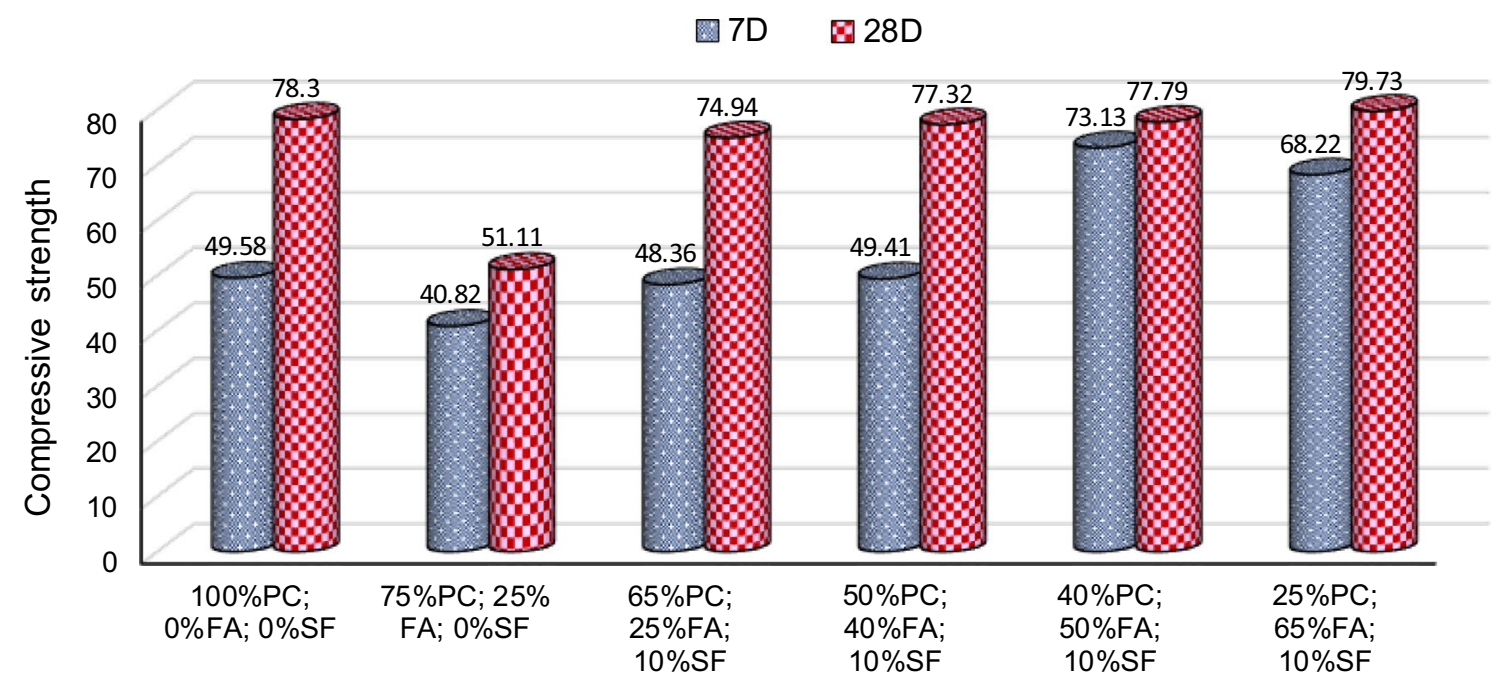

Concrete mixes

Fig. 5 Compressive strength of SCHPC

Fig. 6 Compressive strength of SCHPC at different curing ages

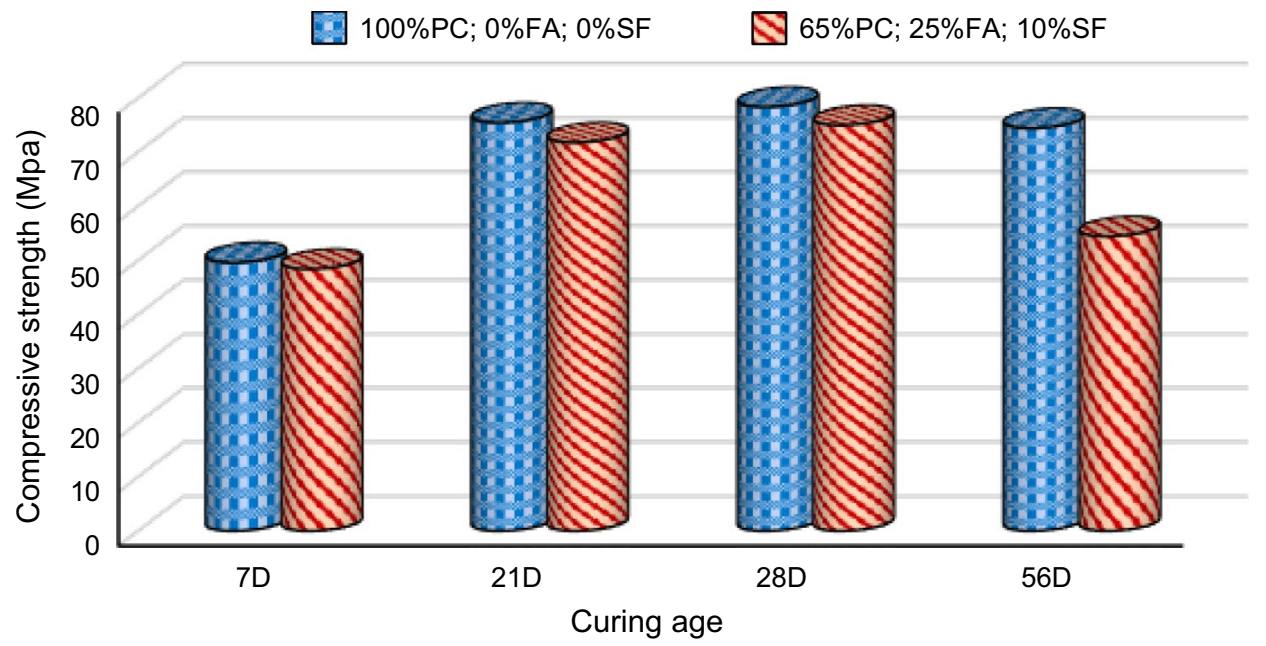

SN Applied Sciences A SPRINGER NATURE journal 
containing 25\% FA with 0\%SF is 35\% lower than the control (OPC). This is due to the slow pozzolanic reaction and dilution effect of FA. Nonetheless, owing to the high pozzolanic reaction and the micro-filler effect of SF than that of FA, the compressive strength of Portland-fly ash-silica fume concrete was improved. Moreover, the particle sizes of SF are smaller than that of FA, thus resulting in an increase in the pozzolanic reaction between $\mathrm{Ca}(\mathrm{OH})_{2}$ from hydration products and the $\mathrm{SiO}_{2}$ in the SF. SF is very effective in the development of $\operatorname{HPC}[9,44]$.

In addition, results showed that the rapid and highest strength development occurred between the ages of 7 and 28 days as indicated by Figs. 5 and 6. Also, the compressive strength values at the age of 28 days varied between 51.11 and $79.73 \mathrm{MPa}$. Maximum compressive strength of $79.73 \mathrm{MPa}$ was obtained by $25 \% \mathrm{PC}$; $65 \% \mathrm{FA}$; $10 \% \mathrm{SF}$ at 28 days and the cement content of this mixture is only $146.88 \mathrm{~kg} / \mathrm{m}^{3}$. Furthermore, the 7-days compressive strength of SCHPC with $50 \% \mathrm{FA} ; 10 \% \mathrm{SF}$ and $65 \% \mathrm{FA} ; 10 \% \mathrm{SF}$ is greater than the 7-days compressive strength of control specimen. Owing to the pozzolanic reaction and the finer particles of SF, it leads to the densification of the microstructure, the enhanced bond strength between the paste and aggregate and increase the compressive strength of SCHPC. Silica fume aids in dispersing flocculated cement grains in fresh concrete mixtures, thus, increasing the free water available for hydration [37].

The compressive strength of SCHPC at different curing ages of 7 days to 56 days is presented in Fig. 6 . It is noticed that SF increases the early compressive strength of Portland-fly ash-silica fume concrete. However, the increase tends to decline in the long-term. The strength development within the cement composites with SF was principally due to the pore size refinement and matrix compaction, reduction of $\mathrm{Ca}(\mathrm{OH})_{2}$ content, and robust cement paste-aggregate surface bond. The formation of dense
$\mathrm{C}-\mathrm{S}-\mathrm{H}$ gel and additional homogenised product at the surface zone results in the speedy strength development of concrete at the early ages. This has been primarily as result of the nucleation of $\mathrm{CH}$ crystals around SF particles in the mixture [18].

It has been noticed that the strength improvement of concrete with SF is fast during the early ages due to the pozzolanic action of SF. In concrete with lower $\mathrm{w} / \mathrm{b}$ ratios, a large amount of unhydrated cementitious material was retained, even after a longer duration. At the early ages, with lower $\mathrm{w} / \mathrm{b}$ ratios, the nonevaporable water content was higher with SF concrete than with plain concrete. However, the nonevaporable water content increased at higher $\mathrm{w} / \mathrm{b}$ ratios and the development of strength continued even at the later ages. Thus, the pozzolanic reactions of the SF continued even in the later ages with the availability of adequate nonevaporable water content in the concrete. The nonavailability of nonevaporable water contents in concrete with lower $\mathrm{w} / \mathrm{b}$ ratios led to the strength deterioration in concrete with SF [35].

\subsection{Splitting tensile strength}

The results of the splitting tensile strength test were presented in Fig. 7. The respective strength values were determined after a period of 28-days. The splitting tensile strength of SCHPC at the age of 28 days increases from 4.84 to $5.86 \mathrm{MPa}$. The addition of FA and SF in the concrete mixes had a progressive response on the splitting tensile strength of concrete. The incorporation of SF improved the splitting tensile strength of Portland-fly ash-silica fume concrete blend [46].

During the tensile test, two of the cylinders corresponding to $40 \% \mathrm{PC} ; 50 \% \mathrm{FA} ; 10 \mathrm{SF}$, was broken into two halves at maximum load. Due to the brittleness of SCHPC and the smaller amount of coarse aggregate and interlocking
Fig. 7 Splitting tensile strength of SCHPC at 28-days

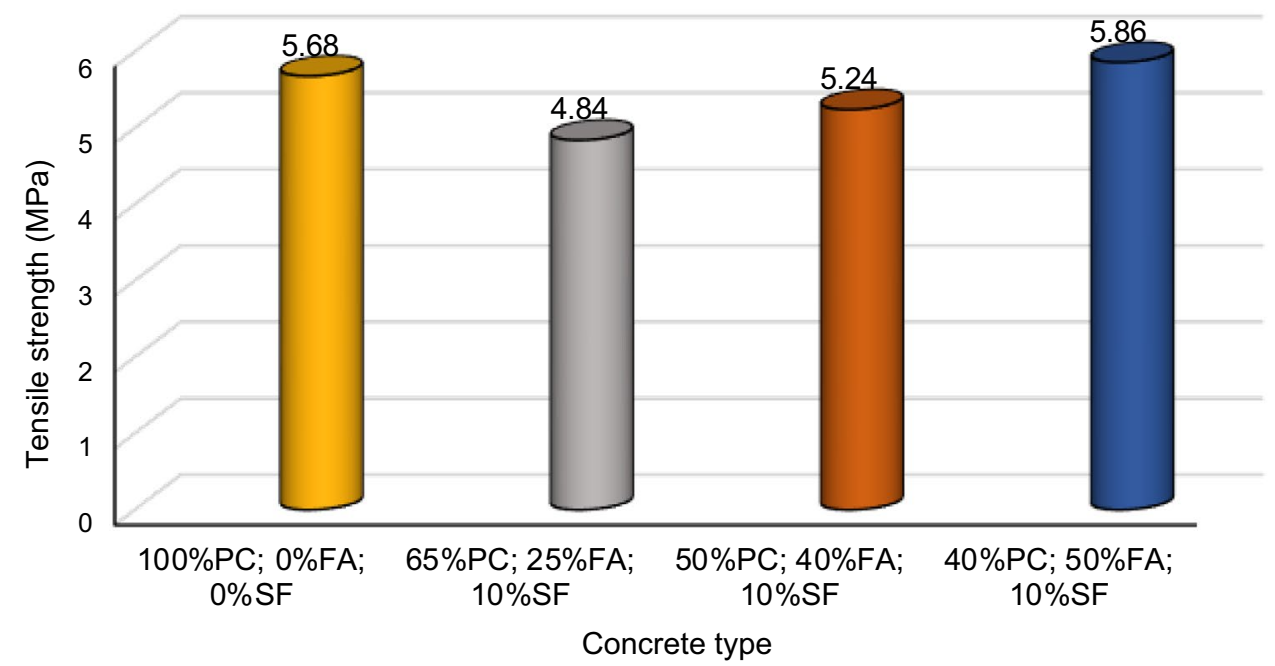




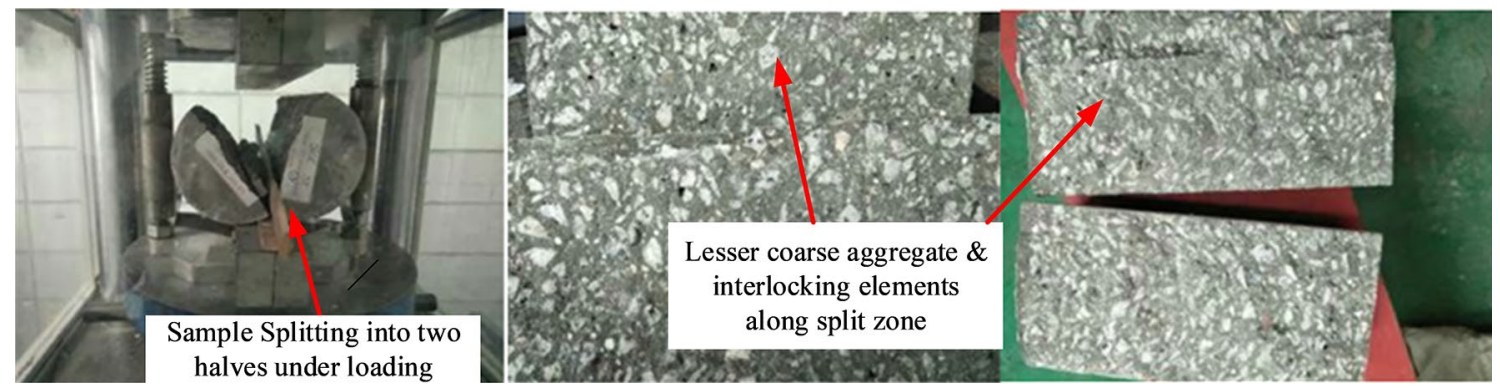

Fig. 8 The failure mode of cylindrical specimen under maximum tensile load

elements, less cohesive stresses were transferred [26]. The tested cylinder specimens are presented in Fig. 8.

\subsection{Static modulus of elasticity}

The static modulus of elasticity of SCHPC is a property that indicates the stiffness of the material and is a fundamental property required for its proper use in various structural application. The results of static modulus of elasticity of the different concrete mixes were summarized in Table 4. The stiffness value of the different SCHPC specimens varied between $64,685 \mathrm{MPa}$ to $86,667 \mathrm{MPa}$.

The stiffness of SCHPC increases as the compressive strength increases. This finding concur with [31]. Moreover, the control specimen exhibits the highest modulus of elasticity of $86,676 \mathrm{MPa}$ at 28 days. Likewise, the rate of increase of compressive strength is higher than that of elastic modulus which is related to high rate of hydration of concrete containing silica fume [31].

On the other hand, a certain level of cement replacement with pozzolans is not only advantageous in terms of cost, but also leads to energy efficiency, ecological and environmental benefits as well as durability properties. Nowadays, researchers have focused on the possibility of practical use of pozzolans as a partial replacement of cement in pursuit of improved long-term strength and durability properties [21].

The modulus of elasticity of the different concrete blends is shown in Fig. 9.

Table 4 Static modulus of elasticity of SCHPC mixes

\begin{tabular}{ll}
\hline Concrete mixes & $\begin{array}{l}\text { Static modulus of } \\
\text { elasticity (MPa) }\end{array}$ \\
\hline 100\%PC; 0\%FA and 0\%SF & 86,676 \\
$50 \% \mathrm{PC} ; 40 \% \mathrm{FA}$ and 10\%SF & 64,685 \\
$40 \% \mathrm{PC} ; 50 \% \mathrm{FA}$ and 10\%SF & 83,500 \\
$25 \% \mathrm{PC} ; 65 \% \mathrm{FA}$ and 10\%SF & 68,054 \\
\hline
\end{tabular}

\section{Conclusions}

This study has reported our novel effort geared toward understanding the influence of partial replacement of Portland cement by $25 \%, 40 \%, 50 \%$, and $65 \%$ class F fly ash and $10 \%$ silica fume on the mechanical properties of SCHPC. Based on the findings, the following conclusions were outlined:

(1) The slump flow of the respective SCHPC lies within class SF1 of EFNARC which is indicative of good filling ability.

(2) All the SCHPC mixes satisfy the requirement for the passing ability class PA2 and the $V$-funnel flow time for all respective SCHPC lies within viscosity class VF2;

(3) The compressive strength of SCHPC containing 25\% FA with $0 \% \mathrm{SF}$ is $35 \%$ lower than that of the Portland cement control, this is due to the slow pozzolanic reaction and dilution effect of FA; Nevertheless, the addition of SF improved the compressive strength of Portland-fly ash-silica fume concrete;

(4) The compressive strength values at the age of 28 days were in the range of 51.11 to $79.73 \mathrm{MPa}$. Maximum compressive strength of $79.73 \mathrm{MPa}$ was obtained by $25 \%$ PC; $65 \%$ FA; $10 \%$ SF and the cement content of this mixture is only $146.88 \mathrm{~kg} / \mathrm{m}^{3}$;

(5) The splitting tensile strength of SCHPC at the age of 28 days increases from 4.84 to $5.86 \mathrm{MPa}$. The addition of FA and SF in the concrete mixes had a progressive response on the splitting tensile strength of concrete. The incorporation of $10 \%$ SF improves the splitting tensile strength.

(6) The static modulus of elasticity values ranges between $64,685 \mathrm{MPa}$ to $86,676 \mathrm{MPa}$ and the control specimen exhibits the highest modulus of elasticity of $86,676 \mathrm{MPa}$.

(7) Incorporating of class F FA and SF in concrete mixtures leads to economic and environmental benefits as well as reducing the heat of hydration of concrete. 


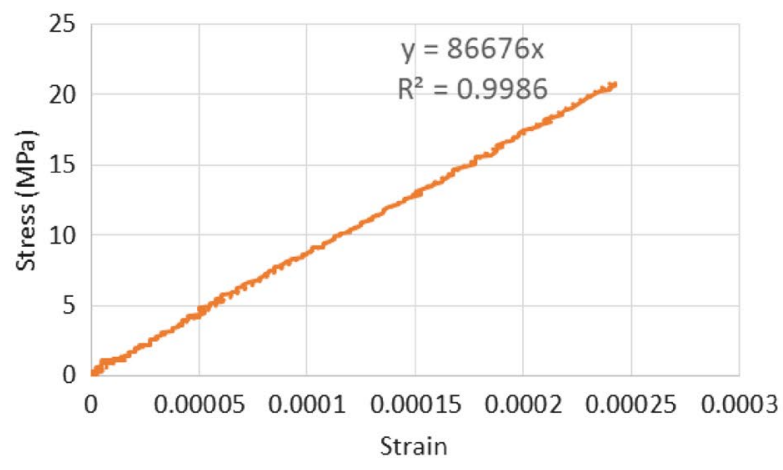

(a) $100 \% \mathrm{PC} ; 0 \% \mathrm{FA} \& 0 \% \mathrm{SF}$

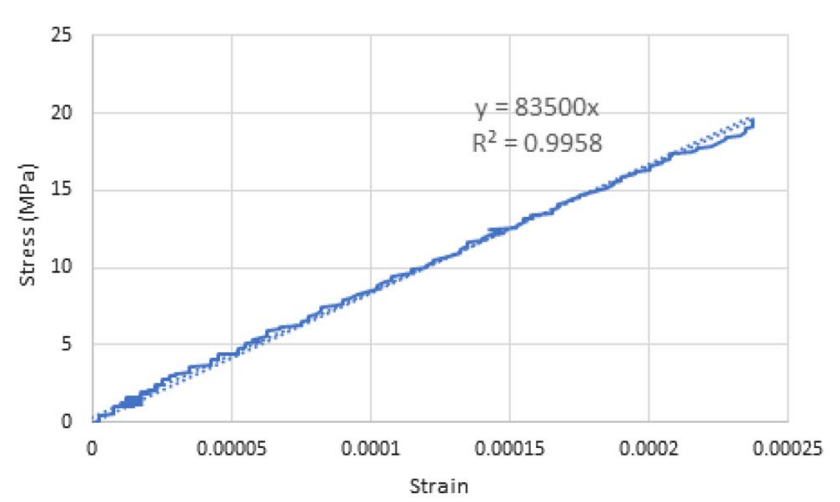

(c) $40 \% \mathrm{PC} ; 50 \% \mathrm{FA} \& 10 \% \mathrm{SF}$

Fig. 9 Modulus of elasticity of SCHPC

Acknowledgements The authors are grateful to the Ministry of Education (MOE), Universiti Teknologi Malaysia and Research Grant Reference No: PY/2017/01513.

\section{Compliance with ethical standards}

Conflict of interest The authors pronounced that there is no conflict of interest associated with this article.

\section{References}

1. Abdullah MH, Abuelgasim R, Rashid AS, Mohdyunus Z (2018) Engineering properties of Tanjung Bin Bottom Ash. SEPKA-ISEED 2018:01006

2. Ahmaruzzaman M (2010) A review on the utilization of fly ash. Prog Energy Combust Sci 36(3):327-363. https://doi. org/10.1016/j.pecs.2009.11.003

3. Aïtcin PC (2003) The durability characteristics of high performance concrete: a review. Cement Concr Compos 25:409-420. https://doi.org/10.1016/S0958-9465(02)00081-1

4. American Standard Testing of Materials (2017) ASTMC494Standard Specification for Chemical Admixtures for Concrete

5. Askari A, Sohrabi MR, Rahmani Y (2011) An investigation into mechanical properties of self compacting concrete incorporating fly ash and silica fume at different ages of curing. Adv

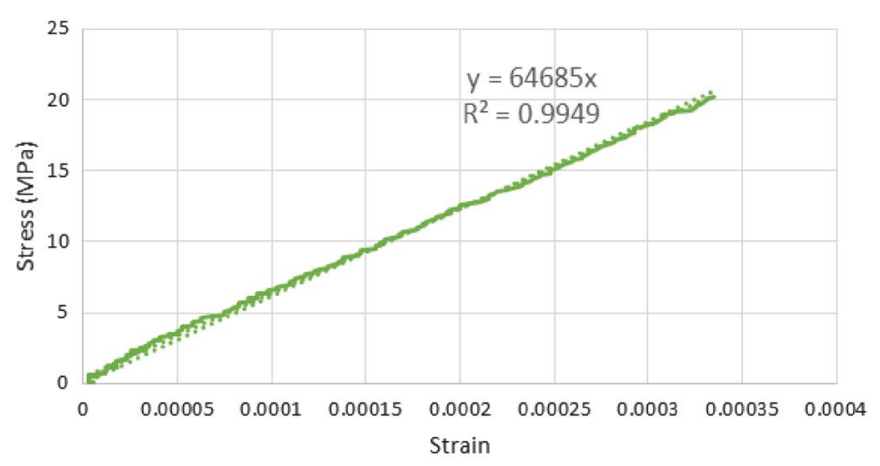

(b) $50 \% \mathrm{PC} ; 40 \% \mathrm{FA} \& 10 \% \mathrm{SF}$

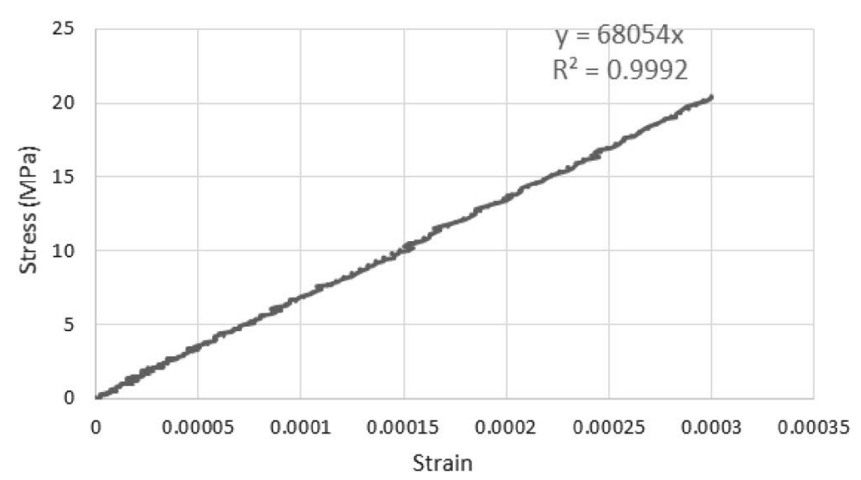

(d) $25 \% \mathrm{PC} ; 65 \% \mathrm{FA} \& 10 \% \mathrm{SF}$
Mater Res 261-263:3-7. https://doi.org/10.4028/www.scien tific.net/amr.261-263.3

6. ASTM C33/C33 M - 13 (2003) Standard specification for concrete aggregates. ASTM International. https://doi.org/10.1520/ $\mathrm{C} 0033$

7. ASTM C496/C496 M-11 (2011) ASTM C496-11 Standard Test Method for Splitting Tensile Strength of Cylindrical Concrete Specimens. Annual Book of ASTM Standards 04:02. https:// doi.org/10.1520/C0496

8. ASTM C618-12a (2003) Standard Specification for Coal Fly Ash and Raw or Calcined Natural Pozzolan for Use. Annual Book of ASTM Standards 04(02):3-6. https://doi.org/10.1520/C0618

9. Benli A, Karataş M, Bakir Y (2017) An experimental study of different curing regimes on the mechanical properties and sorptivity of self-compacting mortars with fly ash and silica fume. Constr Build Mater 144:552-562. https://doi.org/10.1016/j. conbuildmat.2017.03.228

10. Bingöl AF, Tohumcu I (2013) Effects of different curing regimes on the compressive strength properties of self compacting concrete incorporating fly ash and silica fume. Mater Des 51:12-18. https://doi.org/10.1016/j.matdes.2013.03.106

11. BS EN 12350-2. (2009). Testing fresh concrete, Part 2: Slump Test. In Bs En 12350-2:2009

12. BS EN 12390-3 (2009) Testing hardened concrete: part 3, Compressive strength of test specimens

13. Cai B, Wang J, He J, Geng Y (2015) Evaluating $\mathrm{CO}_{2}$ emission performance in China's cement industry: an enterprise perspective. Appl Energy. https://doi.org/10.1016/j.apenergy.2015.11.006 
14. Cwirzen A, Penttala V (2005) Aggregate-cement paste transition zone properties affecting the salt-frost damage of highperformance concretes. Cem Concr Res 35(4):671-679

15. Dotto JMR, Abreu AGD, Molin DCCD, Müller IL (2004) Influence of silica fume addition on concretes physical properties and on corrosion behaviour of reinforcement bars. Cement Concr Compos 26:31-39

16. EFNARC (2002) Specification and Guidelines for Self-Compacting Concrete, vol 44. www.efnarc.org

17. EPG-SCC (2005) The European guidelines for self-compacting concrete. In: Group EP (ed) Specification, production and use. http://citeseerx.ist.psu.edu/viewdoc/download?doi=10.1.1.12 $1.6496 \&$ rep $=$ rep 1 \&type $=$ pdf

18. Gadikota G, Fricker K, Jang S-H, Park A-HA (2015) Carbonation of silicate minerals and industrial wastes and their potential use as sustainable construction materials. https://doi.org/10.1021/ bk-2015-1194.ch012

19. Gonen and Yazicioglu (2007) YaziciogluThe influence of mineral admixtures on the short and long-term performance of concrete. Build Environ 42:3080-3085

20. Hemalatha T, Ramaswamy A (2017) A review on fly ash characteristics - Towards promoting high volume utilization in developing sustainable concrete. J Clean Prod 147:546-559. https:// doi.org/10.1016/j.jclepro.2017.01.114

21. Hossain MM, Karim MR, Hasan M, Hossain MK, Zain MFM (2016) Durability of mortar and concrete made up of pozzolans as a partial replacement of cement: a review. Constr Build Mater 116:128-140. https://doi.org/10.1016/j.conbuildma t.2016.04.147

22. Jalal M, Pouladkhan A, Harandi OF, Jafari D (2015) Comparative study on effects of Class F fly ash, nano silica and silica fume on properties of high performance self compacting concrete. Constr Build Mater 94:90-104. https://doi.org/10.1016/j.conbu ildmat.2015.07.001

23. Jo BW, Sikandar MA, Baloch Z, Naseer A, Jan N, Jamal Q (2018) Effect of $w / b$ ratio and binder content on the properties of selfcompacting high performance concrete (SCHPC). J Ceram Process Res 19(2):171-178

24. Khan MI, Siddique R (2011) Utilization of silica fume in concrete: review of durability properties. Resour Conserv Recycl 57(11):30-35. https://doi.org/10.1016/j.resconrec.2011.09.016

25. Khayat KH, Bickley J, Lessard M (2000) Performance of self-consolidating concrete for casting basement and foundation walls. ACI Mater J 97:374-380

26. Korte S, Boel V, De Corte W, De Schutter G (2013). Fracture Behaviour of Self-Compacting Concrete Compared To. Pro 90, (September), 317-324. http://hdl.handle.net/1854/LU-4148321

27. Le HT, Müller M, Siewert K, Ludwig HM (2015) The mix design for self-compacting high performance concrete containing various mineral admixtures. Mater Des. https://doi.org/10.1016/j.matde s.2015.01.006

28. Lee ST, Moon HY, Swamy RN (2005) Sulfate attack and role of silica fume in resisting strength loss. Cem Concr Compos J 27(1):65-76

29. Liew KM, Sojobi AO, Zhang LW (2017) Green concrete: prospects and challenges. Constr Build Mater 156:1063-1095. https://doi. org/10.1016/j.conbuildmat.2017.09.008

30. Nagaratnam BH, Faheem A, Rahman ME, Mannan A, Leblouba $M$ (2015) Mechanical and durability properties of medium strength self-compacting concrete with high-volume fly ash and blended aggregates. Periodica Polytechnica Civil Engineering 59(2):155-164

31. Nassif HH, Najm H, Suksawang N (2005) Effect of pozzolanic materials and curing methods on the elastic modulus of HPC. Cem Concr Compos 27(6):661-670. https://doi.org/10.1016/j. cemconcomp.2004.12.005
32. Okamura H, Ouchi M (2007) Self-compacting concrete. J Adv Concr Technol. https://doi.org/10.3151/jact.1.5

33. Paris JM, Roessler JG, Ferraro CC, Deford HD, Townsend TG (2016) A review of waste products utilized as supplements to Portland cement in concrete. J Clean Prod 121:1-18. https://doi. org/10.1016/j.jclepro.2016.02.013

34. Poon CS, Lam L, Wong YL (2000) Study on high strength concrete prepared with large volumes of low calcium fly ash. Cem Concr Res 30(3):447-455. https://doi.org/10.1016/S0008 -8846(99)00271-9

35. Rao GA (2001) Development of strength with age of mortars containing silica fume. Cem Concr Res 31(8):1141-1146. https ://doi.org/10.1016/S0008-8846(01)00540-3

36. Sadr Momtazi A, Tahmouresi B, Kohani Khoshkbijari R (2016) An investigation on mechanical properties and durability of concrete containing silica fume and fly ash. Civ Eng J 2(5):189-196. https://doi.org/10.28991/cej-2016-00000025

37. Safiuddin M, Zain MFM (2005) Effects of silica fume and fly ash on the properties of high performance concrete. In: Proceedings of the annual conference on Canadian society for civil engineering, 2005

38. Samhitha KV, Reddy VS, Rao MVS, Shrihari S (2019) Performance evaluation of high-strength high-volume fly ash concrete. Int J Recent Technol Eng 8(3):5990-5994. https://doi.org/10.35940/ ijrte.C5928.098319

39. Shehata MH, Thomas MDA (2002) Use of ternary blends containing silica fume and fly ash to suppress expansion due to alkali-silica reaction in concrete. Cem Concr Res. https://doi. org/10.1016/S0008-8846(01)00680-9

40. Siddique R (2011) Properties of self-compacting concrete containing class F fly ash. Mater Des 32(3):1501-1507. https://doi. org/10.1016/j.matdes.2010.08.043

41. Supino S, Malandrino O, Testa M, Sica D (2016) Sustainability in the EU cement industry: the Italian and German experiences. J Clean Prod 112:430-442. https://doi.org/10.1016/j.jclep ro.2015.09.022

42. Thirumal JR, Harish R (2016) Performance study of self-compacting concrete by fly ash and silica fume for sustainability in building construction. Key Eng Mater 692(692):74-81. https:// doi.org/10.4028/www.scientific.net/KEM.692.74

43. Thomas MDA, Shehata MH (1999) Use of ternary cementitious systems containing SF and FA in concrete. Cem Concr Res 29:1207-1214

44. Wongkeo W, Thongsanitgarn $P$, Ngamjarurojana A, Chaipanich A (2014) Compressive strength and chloride resistance of selfcompacting concrete containing high level fly ash and silica fume. Mater Des 64:261-269. https://doi.org/10.1016/j.matde s.2014.07.042

45. Worrrell E, Price L, Martin N, Hendriks C, Ozawa L (2001) Carbon dioxide emissions from the global cement industry. Annu Rev Energy Environ 26:303-329

46. Wu W, Wang R, Zhu C, Meng Q (2018) The effect of fly ash and silica fume on mechanical properties and durability of coral aggregate concrete. Constr Build Mater 185:69-78. https://doi. org/10.1016/j.conbuildmat.2018.06.097

47. Yazici $\mathrm{H}$ (2008) The effect of silica fume and high-volume Class $C$ fly ash on mechanical properties, chloride penetration and freeze-thaw resistance of self-compacting concrete. Constr Build Mater 22(4):456-462. https://doi.org/10.1016/j.conbu ildmat.2007.01.002

Publisher's Note Springer Nature remains neutral with regard to jurisdictional claims in published maps and institutional affiliations. 